\title{
Seismic studies of a bottom simulating reflection related to gas hydrate beneath the continental margin of the Beaufort Sea
}

\author{
K. Andreassen \\ Institute of Biology and Geology, University of Tromsø, Tromsø, Norway \\ P. E. Hart and A. Grantz \\ U.S. Geological Survey, Menlo Park, California
}

\begin{abstract}
The upper continental margin of the Beaufort Sea, north of Alaska, is underlain by a strong bottom simulating reflection (BSR) that lies 300 to $700 \mathrm{~m}$ beneath the seafloor and corresponds to the phase boundary between interstitial water and natural gas below and solid gas hydrate above. BSRs of similar origin are common worldwide, where they are usually interpreted to mark the base of gas hydrate-bearing clastic sediment, with or without underlying free gas in the sediment. Surprisingly little is known about the origin of these strong reflections. In this paper we analyze the contrasting physical properties which produce BSRs by comparing synthetic BSR amplitudes and waveforms for varying sourcereceiver offsets with multichannel seismic reflection data across the well-developed BSR of the Beaufort Sea. In order to discriminate whether free gas is present under the BSR or not, it was necessary to supplement near-vertical incidence data with prestack offset data. The amplitude-versus-offset (AVO) analysis indicates that the BSR is produced mainly by the existence of free gas in the clastic sediments beneath the BSR. The zone of free gas is, based on vertical incidence synthetics, estimated to be thinner than $11-16 \mathrm{~m}$. It is possibly thicker than $16 \mathrm{~m}$ if the gas concentration decreases with depth. Saturation of gas hydrate in the sediment above the BSR is tentatively estimated from the AVO modeling to be less than $10 \%$ of the pore volume.
\end{abstract}

\section{Introduction}

A bottom simulating reflection (BSR) at a depth corresponding approximately to the base of the methane hydrate stability field is the most widely used indicator of the presence of gas hydrate accumulations beneath the seabed. BSRs are observed worldwide on reflection seismic data from continental margins [Kvenvolden and Barnard, 1983; Kvenvolden et al., 1993] and are commonly assumed to mark an interface between high-velocity gas hydrate and underlying sediments of normal velocity [Stoll and Bryan, 1979; Hyndman and Spence, 1992] or sediments of low velocity containing free gas [Dillon and Paull, 1983; Miller et al., 1991]. BSRs that lie at the approximate position of the base of the gas hydrate stability field are characterized by high reflection amplitude and negative polarity, indicating that the BSR represents a strong decrease in acoustic impedance. A wealth of ideas regarding the significance of natural gas hydrates have been presented. Gas hydrates may have a significant effect on global climate change, may constitute a source of natural gas [Kvenvolden, 1988; 1993], and may dissociate and cause slope failure on continental margins [McIver, 1982; Kayen and Lee, 1991]. Many investigators are developing models to estimate the amounts of hydrate or free gas associated with the BSR [Miller

Copyright 1995 by the American Geophysical Union.

Paper number 95JB00961.

0148-0227/95/95JB-00961\$05.00 et al., 1991; Hyndman and Spence, 1992; Lee et al., 1993; Singh et al., 1993; Minshull et al., 1994], but few of these models are constrained by independent drilling or sample or laboratory data. Little is therefore known about how significant the role of natural gas hydrates is in the geological system in which they are involved.

Seismic reflection data suggest that an extensive accumulation of gas hydrate underlies the outermost continental shelf, slope, and upper continental rise of the Beaufort Sea north of Alaska (Figure 1) [Grantz and Dinter, 1980; Kvenvolden and Grantz, 1990]. The gas hydrate accumulations are inferred from the presence of a strong BSR that lies 300 to $700 \mathrm{~m}$ beneath the seafloor. These depths closely approximate the base of the methane hydrate stability field [MacLeod, 1982], indicating that this strong reflection event marks the base of hydrate-bearing sediments. This interpretation is supported by high reflection amplitudes and reversed reflection polarity of the BSR with respect to the seafloor reflection. The BSR occurs where the water depth exceeds $400 \mathrm{~m}$, and it either dies out or becomes indistinguishable from the gently basinward dipping reflections of the Canada Basin in the Arctic Ocean where the water depth exceeds $2,900 \mathrm{~m}$.

In this paper we examine the nature of the BSR through seismic modeling of its amplitude and waveform with varying source-receiver offsets. Amplitude-versus-offset (AVO) can be an important indicator of free gas at an interface and has been an increasingly important technique in the oil and gas industry for the last decade. The AVO method has been used in recent hydrate BSR studies by Hyndman and Spence [1992], Bangs et al. [1993], and Ecker and Lumley [1993]. 


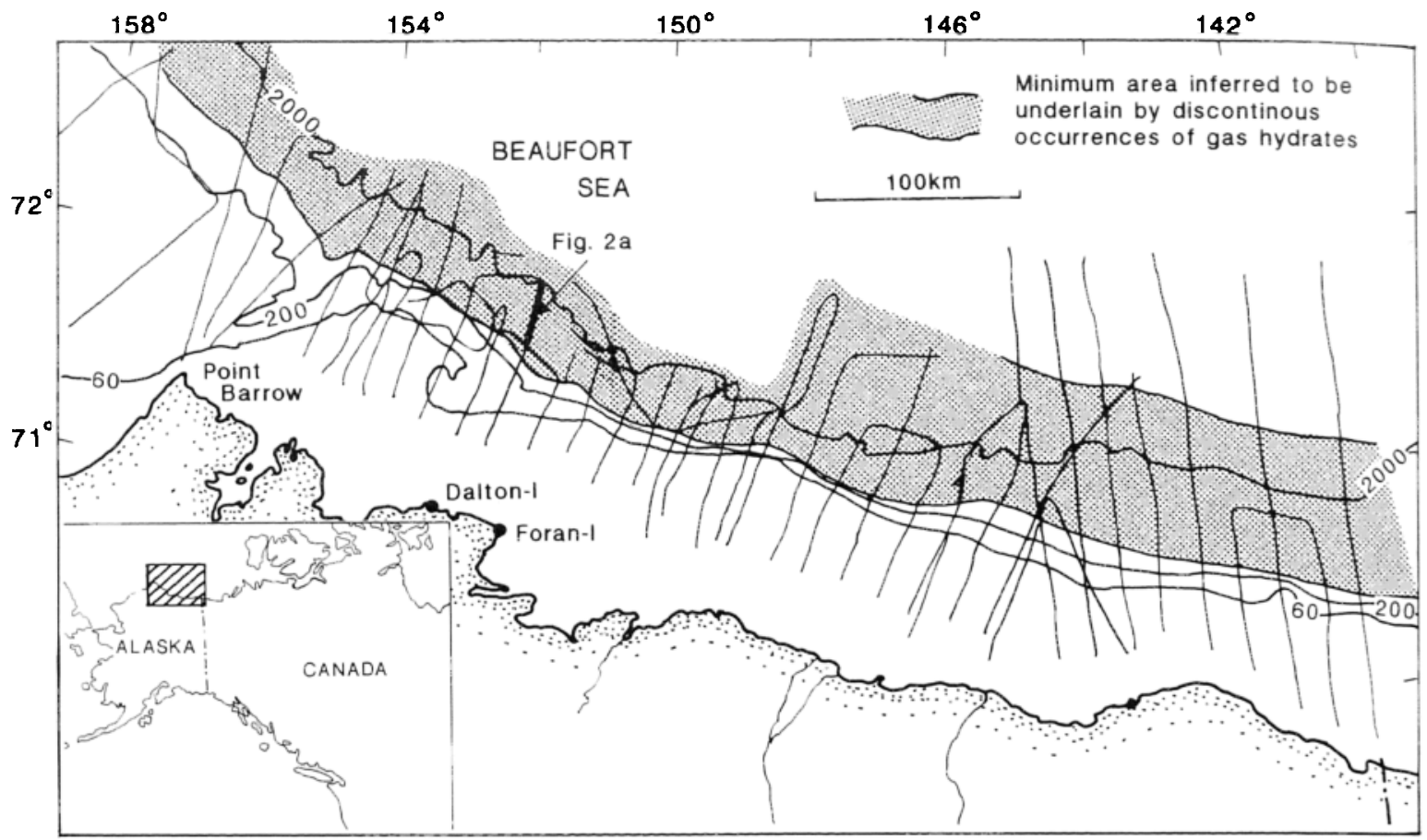

Figure 1. Beaufort Sea study area showing areal extent of the interpreted gas hydrate and location of seismic lines used in the mapping. The seismic line segment shown in Figure $2 a$ is indicated by the thick black line, and the solid circles show location of the wells mentioned in the text.

Seismic line 769 from the Beaufort Sea, which shows a strong BSR (Figures 1 and 2), was studied in detail and compared with synthetic seismograms for a variety of models. Prior to modeling, physical properties of sediments partially saturated with gas hydrate or with free gas were computed, to provide a basis for the modeling and a framework for interpreting our results.

The seismic reflection data used in this study (Figure 1) were collected by the U.S. Geological Survey in 1977 from the R/V S.P. Lee [Grantz et al., 1982]. The acquisition system included a 24-channel hydrophone streamer with a 2400-m active section and a five air gun $22.7 \mathrm{~L}$ source array. The 24 -fold data were reprocessed for the present study to preserve relative reflection amplitudes.

\section{Geologic Setting}

Hydrate deposits of the Beaufort Sea occur in the upper part of a progradational sedimentary prism constructed across the rift that created the passive continental margin north of Alaska [Grantz et al., 1990], about 133 Ma. Extrapolation from test wells on the North Slope of Alaska and inner shelf suggests that the hydrate-bearing beds in the western Beaufort Sea near line 769 (Figure 1) are intertongued intradelta deposits of the Sagavanirktok Formation and prodelta deposits of the Channing Formation, of Neogene and possibly late Paleogene age. These deposits have been down-dropped toward the Canada Basin to the north on a series of listric normal faults. Beneath the western North Slope the Sagavanirktok facies consist of fluvial-deltaic and shallow marine shale, siltstone, sandstone, conglomerate, and coal and have average organic contents of 0.65 and $1.99 \%$ type III (terrestrial) kerogen in the coastal Foran-1 and Dalton-1 wells (Figure 1) [Magoon and Bird, 1988]. Although these beds are immature for the generation of petroleum, Tissot and Welte [1978] note that, in general, important amounts of methane can be generated in such beds, especially if organic matter of type III is present. The presence of the strong BSR on line 769 beneath local bathymetric highs could be a result of gas migration along the BSR. The location of the BSR to areas lacking normal faults suggests that the gas associated with the BSR is not thermogenic gas that migrated upsection from within or below the oil window. The assumption of high content of organic matter in the inferred gas hydratebearing sediments favors a biogenic origin of the gas.

\section{Reflection Characteristics of the BSR Area}

The BSR beneath the Beaufort Sea (Figure 1) has the following seismic reflection characteristics:

1. The BSR has high reflection amplitude and reversed polarity relative to the seafloor reflection (Figures $2 b$ and $2 c$ ). The BSR therefore marks an interface at which there is a significant decrease in acoustic impedance.

2. No consistent reflection that could represent the shallowmost limit of gas hydrate is present.

3. The interval velocity above the BSR is not measurably higher than that at corresponding subbottom depths where the BSR is not present. This observation may indicate that gas hydrate deposits are not everywhere underlain by BSRs. An alternative interpretation is that the concentration of gas hydrate in the sediments above the BSR is low or that gas hydrate is confined to a thin interval above the BSR and therefore does not affect the interval velocity above the BSR enough to be detected with these data. Average interval velocity between the seafloor reflection and the BSR is approximately $1750 \mathrm{~m} / \mathrm{s}$ for the section of the line shown in Figure 2a.

4. Bathymetric highs on the seafloor are commonly underlain by high-amplitude BSRs, and BSRs are commonly 
LINE 769

a)
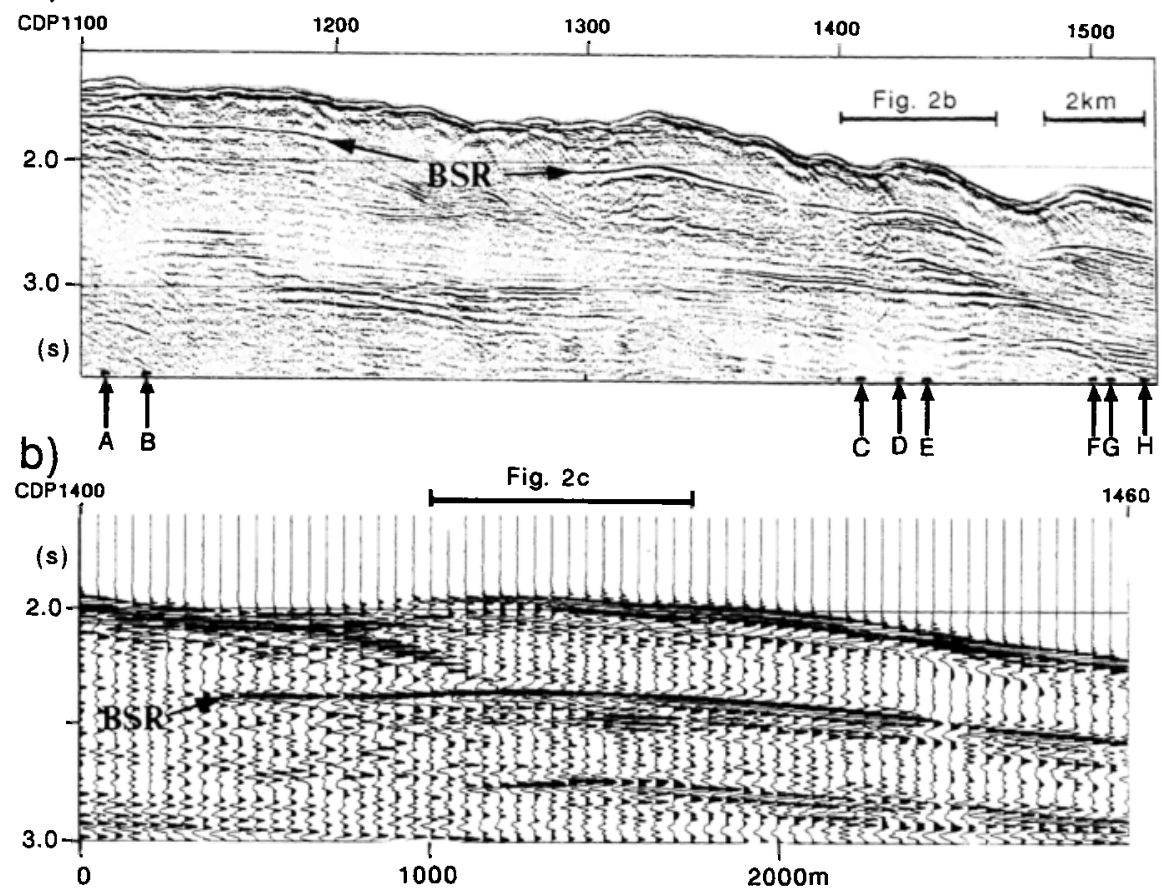

c)

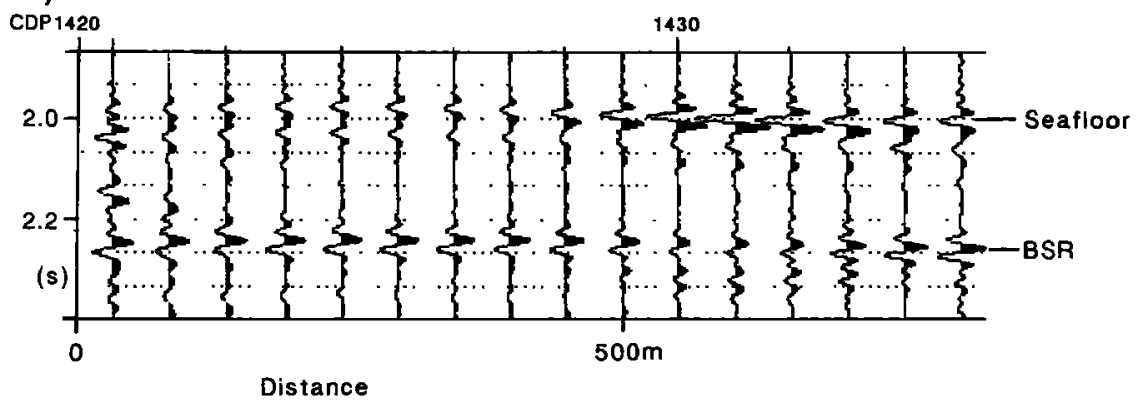

Figure 2. (a) Relative amplitude section of unmigrated multichannel seismic line 769 showing strong bottom simulating reflection (BSR) segments (location of the seismic section is shown in Figure 1). Letters A-H indicate locations for detailed near-trace displays (Figure 3). (b) A portion of line 769 illustrating the shape of the seafloor and BSR reflections. (c) Detail display from line 769 illustrating the seismic waveforms of the BSR and seafloor reflections.

much lower in amplitude or absent beneath the intervening bathymetric lows (Figure 2a). The high reflection amplitudes beneath the bathymetric highs have been attributed to free gas trapped beneath the upward convex base of a seafloorsimulating body of sediment made impermeable by gas hydrate [Grantz et al., 1987].

5. The BSR crosscuts bedding plane reflections, which indicate that it is not a bedding plane reflection.

6. Amplitudes of reflections that crosscut the BSR are often increased immediately below the BSR (Figure 2a).

\section{BSR Reflection Coefficients}

BSRs associated with gas hydrate are characterized by large negative reflection coefficients, indicating that the BSR originates at an interface with a strong decrease in acoustic impedance. For example, offshore Peru, reflection coefficients of hydrate BSRs are estimated to average -0.135 and reach values as large as -0.2 to -0.25 [Miller et al., 1991]. Values of -0.1 to -0.15 are calculated for BSR amplitudes offshore Vancouver Island [Hyndman and Spence, 1992], and BSR amplitudes, and reflection coefficients, offshore Colombia are reported to exceed those of the seabed reflection, indicating reflection coefficients of -0.2 to -0.3 [Minshull et al., 1994].

Near traces from the Beaufort Sea profile 769, shown in Figure 3 (locations labeled $\mathrm{A}-\mathrm{H}$ in Figure 2a) display high reflection amplitude and opposite polarity of the BSR relative to the seafloor reflection. Estimates of the BSR reflection coefficients were obtained by comparing the BSR amplitude with the amplitude of the seafloor reflection [Anstey, 1977]. The seafloor reflection coefficient was estimated to be approximately 0.25 to 0.3 , based on the following estimates of compressional velocity $\left(V_{p}\right)$ and density $(\rho)$ of the seafloor sediments: $V_{p \text { seawater }}=1460-1480 \mathrm{~m} / \mathrm{s} ; \rho_{\text {scawater }}=1000-1020$ $\mathrm{kg} / \mathrm{m}^{3} ; V_{p \text { scancor sedinents }}=1500-1600 \mathrm{~m} / \mathrm{s} ;$ and $\rho_{\text {seulloor sediments }}=$ $1600-1700 \mathrm{~kg} / \mathrm{m}^{3}$, which are reasonable estimates for seafloor 


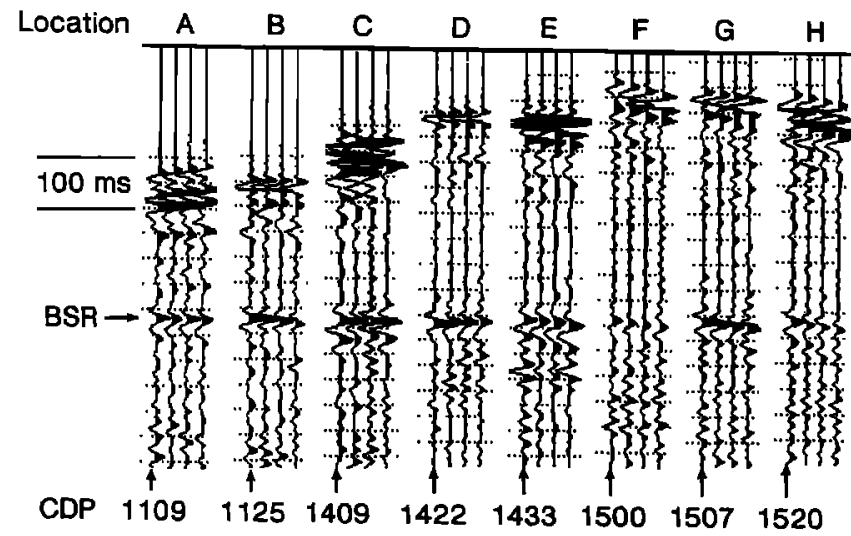

Figure 3. Near-offset traces from line 769. Locations of the sections are indicated in Figure 2a.

acoustic properties [Hamilton, 1978; Hamilton and Bachman, 1982]. The reflection coefficient of the seafloor was also estimated by comparing the relative amplitude of the primary seafloor reflection with its first multiple [Anstey, 1977; Warner, 1990]. The reflection coefficient $R$ is estimated to be $A_{m} / A_{p}$, where $A_{m}$ and $A_{p}$ are the amplitudes of the primary and first multiple reflections from the seafloor. The amplitude spreading correction used for the multiple was twice the correction factor used for the seafloor reflection, as the path length of the multiple reflection is double that of the primary. To avoid the effect of any variations in reflection coefficient with incidence angle, the primary amplitudes were measured from the nearest offset traces and the multiple amplitudes from traces with twice that offset. A seafloor reflection coefficient of about 0.28 is obtained using this method at an area where the seafloor is flat and where water depth is about $1450 \mathrm{~m}$.

The near-trace amplitudes of the BSR along profile 769 are commonly 60 to $80 \%$ of those of the seafloor reflection (Figure 3 ) and in places are even higher than the seafloor reflection amplitudes. Reflection coefficients for the high-amplitude segments of the BSR on line 769 are therefore commonly of the order of -0.15 to -0.24 , with highs around -0.3 .

\section{Physical Properties Used in the Modeling}

\section{Water-Saturated Sediments}

Compressional wave velocity $\left(V_{p}\right)$ of water-saturated sediments was calculated from stacking velocities of the Beaufort Sea seismic profiles at locations where no BSR is observed, giving an average interval velocity of about $1750 \mathrm{~m} / \mathrm{s}$ between the seafloor reflection and the BSR. Densities are obtained from the data of Hamilton [1979], and porosities are estimated from Hamilton and Bachman [1982] and Lee et al. [1993]. Poisson's ratios for water-saturated sediments are estimated from Castagna et al.'s [1985] relation between Poisson's ratio and $V_{p}$ (Figure 4) and from Hamilton [1979]. For water-saturated sediments at the depth of the BSR, compressional wave velocity is estimated to be approximately $1900 \mathrm{~m} / \mathrm{s}$, density is $1900 \mathrm{~kg} / \mathrm{m}^{3}$, porosity is $40 \%$, and Poisson's ratio is 0.47 .

\section{Gas Hydrate-Bearing Sediments Above the BSR}

Gas hydrate is an icelike solid wherein gas molecules are included within a crystalline water lattice, similar to ice, except that the crystalline structure is stabilized by guest molecules of gas. Submarine gas hydrates sampled to date generally contain methane accompanied by varying amounts of heavier hydrocarbon gases such as ethane and propane [Sloan, 1990].

The density of pure gas hydrate is approximately $920-930$ $\mathrm{kg} / \mathrm{m}^{3}$ [Whalley, 1980, Kvenvolden and McDonald, 1985; Mathews and von Huene, 1985]. In the present study the threephase weighted average equation of Zimmerman and King [1986] is used to estimate $\rho$, the bulk density of gas hydratebearing sediments.

Compressional wave velocity $\left(V_{p}\right)$ of pure gas hydrate is approximately 3300-3800 m/s [Whalley, 1980; Sloan, 1990]. The formation of gas hydrate in sediments involves the replacement of pore fluid with solid gas hydrate, a process which is not well understood [Sloan, 1990]. Moreover, little is known about how gas hydrate affects the compressional wave velocity of the sediments. The three-phase time average equation (Figure 5, labeled "Time average equa.") was proposed by Pearson et al., [1986] for estimating $V_{p}$ of hydrate-beaning sediments. The time average relationship for calculating compressional wave velocity has been shown to be applicable for consolidated porous rocks [Zimmerman and King, 1986], with porosities between 0 and 25\% [Pandit and King, 1979], but it is inapplicable to unconsolidated sediments unless an artificially low value is used for the rock matrix velocity [Zimmerman and King, 1986]. Note also that the time average equation gives a volume average of the velocity of the medium components and that the method does not take into account the physical properties of the rock such as elastic moduli and density. The time average equation of Figure 5 clearly underestimates compressional velocity for hydrate-bearing sediments.

Compressional wave velocity $V_{p}$ and shear velocity $V_{s}$ can also be calculated for gas hydrate-bearing sediment applying the Gassmann [1951] equations

and

$$
V_{\mathrm{p}}=((K+4 / 3 G) / \rho)^{1 / 2}
$$

$$
V_{s}=(G / \rho)^{1 / 2}
$$

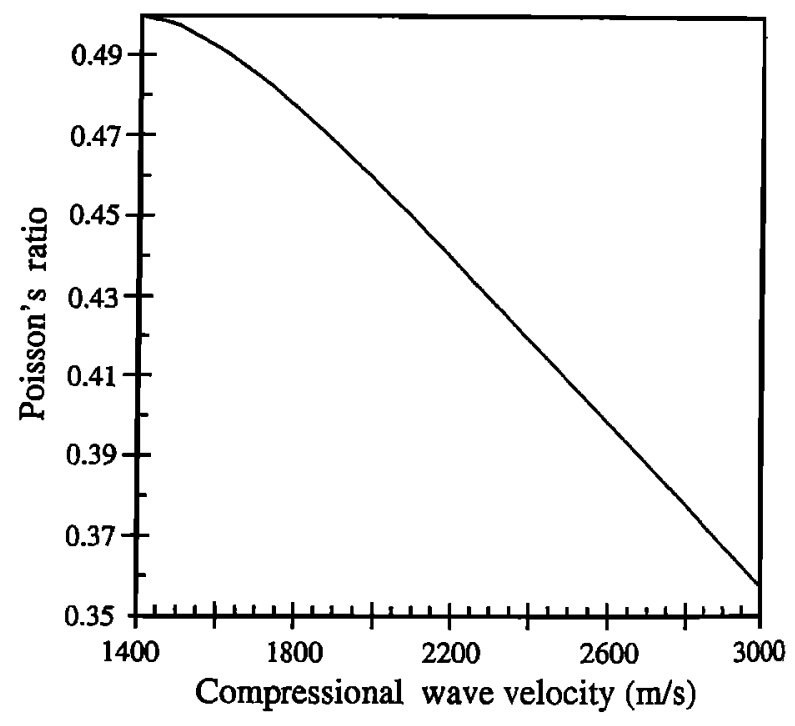

Figure 4. The relationship between Poisson's ratio and compressional wave velocity $\left(V_{p}\right)$ for clastic sediments, calculated using the equation $V_{p}=1.16 V_{s}+1.36$ of Castagna et al. [1985]. 


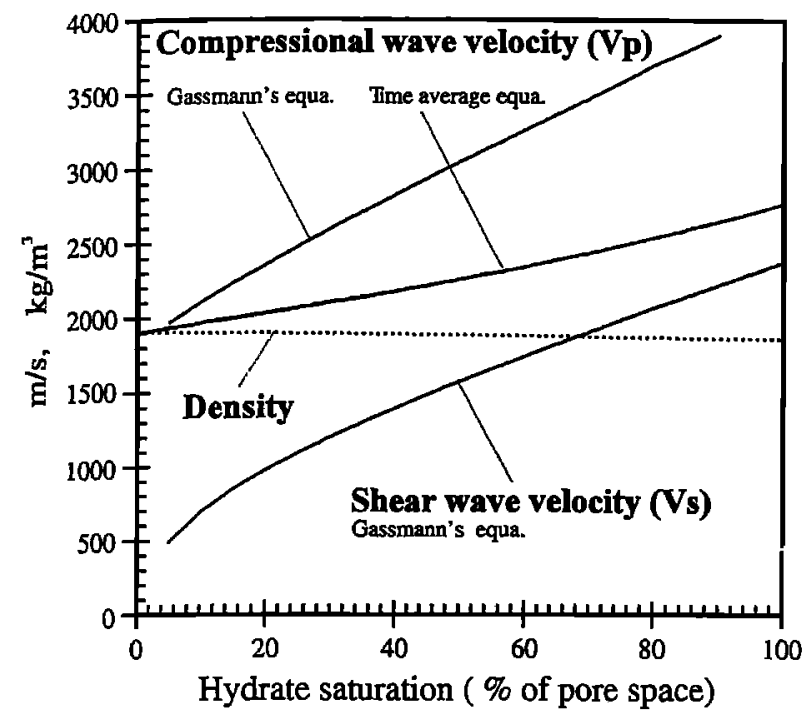

Figure 5. Calculated relationship for bulk density, compressional wave velocity, and shear wave velocity versus gas hydrate saturation, based on the time average equation and Gassmann's [1951] equations.

and are displayed in Figure 5 (labeled "Gassmann's equa."). The bulk modulus of the sediment, $K$, and the sediment shear modulus, $G$, are calculated using an "inclusion theory" that was applied to permafrost sediments by Kuster and Toksöz [1974] and that has been tested by experimental and theoretical studies on partially frozen sediments by Zimmerman and King [1986], who also give a detailed explanation of the calculations. The gas hydrate moduli used in the calculations are obtained from Sloan [1990]. AVO model parameters are often expressed as $V_{p}$ and Poisson's ratio, $\sigma$, that can be calculated from

$$
\sigma=\left\{1 / 2\left(V_{p} / V_{s}\right)^{2}-1\right\} /\left\{\left(V_{p} / V_{s}\right)^{2}-1\right\}
$$

Poisson's ratio versus gas hydrate saturation is displayed in Figure 6 (hydrate curve). The equations of Kuster and Toksöz [1974] and Gassmann [1951] are probably suitable for gas hydrate-saturations of $30 \%$ or greater, according to Zimmerman and King [1986] and Curtis [1992]. The model is probably not applicable to sediment with low concentrations of gas hydrate. Another problem is that this model is approximate only for very sand-rich sediments. Gas hydrates, however, commonly occur in clay-rich sediment, and Castagna et al. [1985] have shown that $V_{p} / V_{s}$ and hence the Poisson's ratio $\sigma$ increase with clay content. The hydrate curve of Figure 6 will provide a minimum estimate of the Poisson's ratio. Establishing a complete theoretical model for gas hydrate-bearing clay-rich sediments is beyond the scope of this paper. In the present study $\boldsymbol{P}$ wave velocities for gas hydrate-bearing sediments at depth of the BSR are estimated from velocity analysis and from the BSR reflection coefficient, as discussed later in this paper, whereas the Poisson's ratios used are obtained from Figure 6 and the Gassmann curve of Figure 5.

\section{Free Gas Beneath the BSR}

Free gas causes a drastic reduction in compressional wave velocity and Poisson's ratio of clastic sediments [Domenico, 1976, 1977; Gregory, 1977a,b; Murphy, 1984; Ostrander,
1984]. Compressional and shear wave velocity, as well as bulk density, are calculated as a percentage of gas saturation in sediments (Figure 7), using the Biot-Gassmann relations as given by Gregory [1977a]. It is clearly demonstrated in Figures 6 and 7 that the largest reduction in $V_{p}$ and in Poisson's ratio occurs for gas saturation between 0 and $5 \%$. $P$ wave velocities between 1200 and $1400 \mathrm{~m} / \mathrm{s}$ are used in the seismic modeling, and density and Poisson's ratios are determined from the relationships shown in Figures 6 and 7.

\section{Modeling the BSR}

The seismic responses of five models (Figure 8 and Table 1) are evaluated in the present paper. The presence of gas hydrate or free gas can strongly affect the compressional wave velocity of clastic sediment, whereas the density will decrease only slightly with increased concentrations of gas hydrate or free gas (Figures 5 and 7). Therefore the models we have evaluated are displayed as velocity models.

For models with no free gas below the BSR (LA and IB in Figure 8), and assuming a velocity of $1900 \mathrm{~m} / \mathrm{s}$ below the BSR, a velocity of at least $2600 \mathrm{~m} / \mathrm{s}$ is needed for the hydrate-bearing sediments above the BSR to obtain a reflection coefficient more negative than -0.15 , as estimated for the BSR on profile 769 . A velocity of $2600 \mathrm{~m} / \mathrm{s}$ is therefore used for hydrate-bearing sediments in these models. For models with free gas under the BSR (IIA, III, and IIC in Figure 8), velocities of 1900-2400 $\mathrm{m} / \mathrm{s}$ are needed for the sediments above the BSR to obtain reflection coefficients of -0.15 to -0.24 , assuming a gas saturation of at least $1 \%$ of the sediment pore volume. Therefore in models with free gas under the BSR a median value of $2150 \mathrm{~m} / \mathrm{s}$ is used for the velocity of hydrate-bearing sediments above the BSR.

We have evaluated models with a thin layer of gas hydrate, in which the hydrate has a uniform concentration (IA and IIA in Figure 8); models with a thin layer of gas hydrate having a gradational increase in hydrate concentration with depth (IB and IIB in Figure 8); and models with no gas hydrate above the

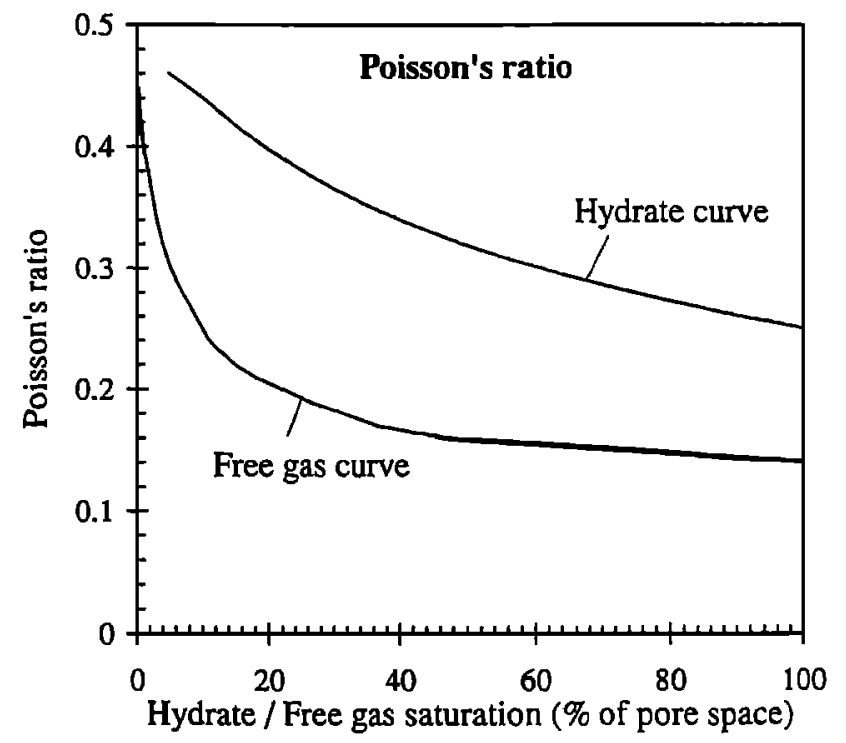

Figure 6. The relationship between Poisson's ratio and saturation of hydrate or free gas in the sediment pore space, calculated from the equations given by Gassmann [1951] and by Gregory [1977a], respectively. 


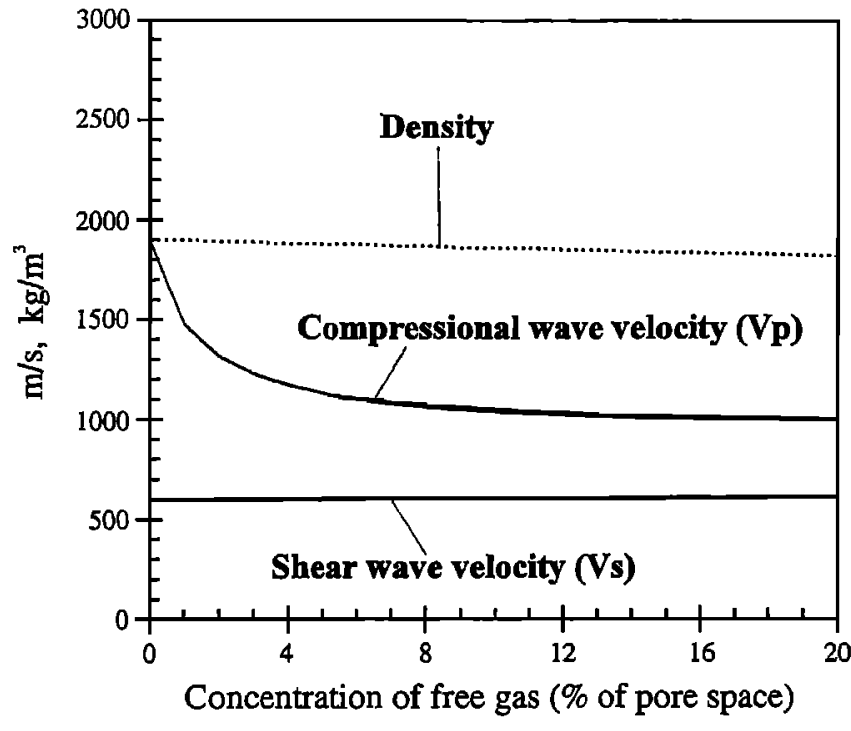

Figure 7. Calculated relationship for bulk density, compressional wave velocity, and shear wave velocity versus contration of free gas in the sediment. The equations used are those given by Gregory [1977a].

BSR (IIC of Figure 8). Free gas under the BSR is modeled in two ways: (1) confined to a thin layer with constant gas concentration and (2) confined to a layer in which the gas concentration decreases with depth (Figure 8, dashed lines).

Synthetic seismograms were constructed for each of the models by estimating a source wavelet from the seafloor reflection in an area where it appears to be free from interference with other reflections.

\section{Near-Vertical Incidence BSR Waveform and Reflection Coefficients of the Models}

The near-vertical seismic traces calculated for the different models presented in Figure 8 are displayed in Figures 9 and 10. Two representative data traces from seismic line 769 are displayed at the right side of the figures for comparison. The histograms above the traces indicate the calculated near-vertical reflection coefficient for each model, and the BSR reflection coefficients, estimated from line 769 , are displayed here as a shaded band between -0.15 and $\mathbf{- 0 . 2 4}$.

\section{Models With No Free Gas Beneath the BSR}

Models with no free gas beneath the BSR and a thin hydrate layer of uniform concentration above give at the depth of the BSR two separate peaks of opposite polarity for layer thicknesses greater than half of the wavelength $\lambda$, which is approximately $22 \mathrm{~ms}$ ( $29 \mathrm{~m}$ of gas hydrate-bearing sediments with a velocity of $2600 \mathrm{~m} / \mathrm{s}$ ) (Figure 9a). These peaks are not observed in the field data (Figure 9a). For hydrate layers thinner than $22 \mathrm{~ms}$ the BSR model waveform is asymmetric with a strong negative peak followed by a slightly smaller positive peak which also differs from the field data traces. Models with increasing hydrate concentration with depth can provide a more symmetric BSR waveform (Figure 9b) and a better fit with the data, for all hydrate thicknesses.

\section{Models With Free Gas Beneath the BSR}

Models with a layer of free gas beneath the BSR up to $22 \mathrm{~ms}$ thick (11-16 $\mathrm{m}$ of sediments with gas saturation between $100 \%$ and $1 \%$, respectively) and models with a thick layer of gas that decreases in concentration with depth both produce BSR reflections that closely match the field data (Figure 10c). A layer with constant hydrate concentration above the BSR will modify the BSR model waveform (Figure 10a), but the correlation with the field data is still reasonable, also for hydrate thicknesses greater than half of the wavelength $(22 \mathrm{~ms}$ or $24 \mathrm{~m}$ of gas hydrate-bearing sediment with a velocity of $2150 \mathrm{~m} / \mathrm{s}$ ) (Figures $10 \mathrm{a}$ and $10 \mathrm{~b}$ ). BSR waveforms similar to the field data are obtained for models with a gradational layer of increasing hydrate saturation with depth as well (Figure 10b). A good fit with the data can be obtained also for models with no hydrate above the BSR if the underlying free gas layer is thinner than $22 \mathrm{~ms}$ (11-16 $\mathrm{m}$ for free gas-bearing sediments). The gas layer can, however, be thicker if it decreases in gas saturation with depth (Figure 10c).

It is apparent from the foregoing analysis that studies of near-vertical seismic data provide information about the best fit models. Using only the near-vertical seismic data, however, we cannot discriminate between models with free gas below the BSR and models without a free gas layer, nor can we estimate the thickness of the hydrate layer.

\section{Amplitude-Versus-Offset (AVO) Analyses}

A great deal of attention has been devoted to using the Poisson's ratio as a direct hydrocarbon indicator ever since the now classic paper on AVO published by Ostrander [1984]. The differences in elastic properties, as quantified by Poisson's ratio, between gas hydrate, free gas, and liquid water are the physical basis for AVO analysis of the BSR. The change of this ratio at an interface directly affects the reflected $P$ wave amplitude as a function of offset on prestack data.

It can be seen from Figures 4 and 6 that a change in Poisson's ratio will occur at the base of gas hydrate-bearing sediment, at the top of gas-bearing sediment, and at an interface with gas hydrate-bearing sediment overlying sediment containing free gas. Changes in concentration levels of both gas hydrate and free gas will affect the Poisson's ratio across the BSR and will hence affect the BSR amplitude variation with offset. The variation in $P$ wave amplitude with offset can be

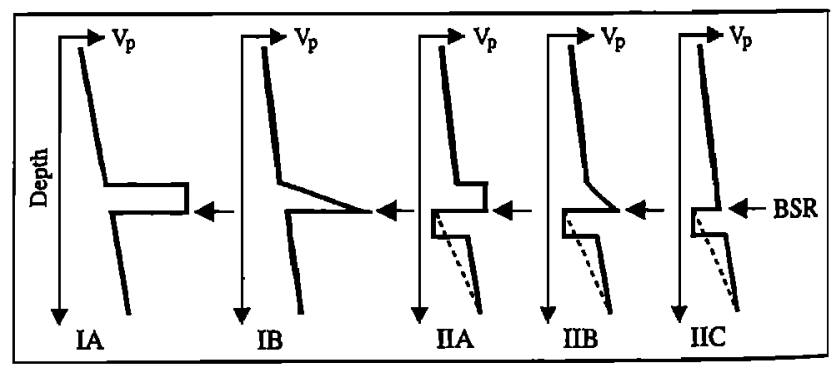

Figure 8. Relative changes in compressional wave velocity for the five modles that have been evaluated. $V_{p}$ is increasing to the right. The values of $V_{p}$ used in the modeling are mentioned and discussed in the paper. Free gas under the BSR is modeled as confined to a thin layer with constant gas concentration or as confined to a layer in which gas concentration decreases with depth, as indicated with the dashed lines. 
Table 1. Model Comparisons

\begin{tabular}{|c|c|c|c|c|c|c|}
\hline \multirow[b]{2}{*}{ Model } & \multicolumn{2}{|c|}{ Qualities } & \multicolumn{2}{|c|}{$\begin{array}{l}\text { Physical Properties } \\
V_{p}, \text { Density, Poisson's Ratio }\end{array}$} & \multirow{2}{*}{$\begin{array}{l}\text { Match With Near-Vertical } \\
\text { Incidence Data }\end{array}$} & \multirow{2}{*}{$\begin{array}{l}\text { Match With } \\
\text { AVO Data }\end{array}$} \\
\hline & Above BSR & Below BSR & Above BSR & Below BSR & & \\
\hline IA & $\begin{array}{l}\text { thin layer of } \\
\text { uniform } \\
\text { hydrate } \\
\text { concentration }\end{array}$ & no free gas & $\begin{array}{c}2600,1860 \\
0.38 / 0.42\end{array}$ & $\begin{array}{l}1900,1900 \\
0.47\end{array}$ & poor & poor \\
\hline IB & $\begin{array}{l}\text { thin layer of } \\
\text { increasing } \\
\text { hydrate } \\
\text { concentration } \\
\text { at depth }\end{array}$ & no free gas & $\begin{array}{r}2600-1900 \\
1860-1900 \\
0.38-0.47\end{array}$ & $\begin{array}{l}1900,1900 \\
0.47\end{array}$ & good & poor \\
\hline IIA & $\begin{array}{l}\text { thin layer of } \\
\text { uniform } \\
\text { hydrate } \\
\text { concentration }\end{array}$ & $\begin{array}{l}\text { free gas in } \\
\text { sediments }\end{array}$ & $\begin{array}{l}2150,1880 \\
0.44\end{array}$ & $\begin{array}{c}1200-1400 \\
1880-1890 \\
0.2-0.3\end{array}$ & $\begin{array}{l}\text { good, for gas layers thinner } \\
\text { than } 22 \mathrm{~ms}(11-16 \mathrm{~m}) \text { or } \\
\text { thicker and with a } \\
\text { gradational base }\end{array}$ & good \\
\hline IIB & $\begin{array}{l}\text { thin layer of } \\
\text { increasing } \\
\text { hydrate } \\
\text { concentration } \\
\text { at depth }\end{array}$ & $\begin{array}{l}\text { free gas in } \\
\text { sediments }\end{array}$ & $\begin{array}{r}2150-1900 \\
1880-1900 \\
0.44-0.47\end{array}$ & $\begin{array}{c}1200-1400 \\
1880-1890 \\
0.2-0.3\end{array}$ & $\begin{array}{l}\text { good, for gas layers thinner } \\
\text { than } 22 \mathrm{~ms}(11-16 \mathrm{~m}) \text { or } \\
\text { thicker and with a } \\
\text { gradational base }\end{array}$ & good \\
\hline IIC & no hydrate & $\begin{array}{l}\text { free gas in } \\
\text { sediments }\end{array}$ & $\begin{array}{l}1900,1900 \\
0.47\end{array}$ & $\begin{array}{c}1200-1400 \\
1880-1890 \\
0.2-0.3\end{array}$ & $\begin{array}{l}\text { good, for gas layers thinner } \\
\text { than } 22 \mathrm{~ms}(11-16 \mathrm{~m}) \text { or } \\
\text { thicker and with a } \\
\text { gradational base }\end{array}$ & $\begin{array}{l}\text { good, if the gas } \\
\text { layer has a } \\
\text { gradational } \\
\text { base }\end{array}$ \\
\hline
\end{tabular}

$V_{p}$ is given in meters per second, and density is given in kilograms per cubic meter.

calculated for different BSR models and can be directly compared with measurements of the real data BSR amplitudeversus-offset. Unfortunately, these measurements are complicated by many factors which affect the recorded amplitude as a function of offset, of which 11 were cited by Ostrander [1984]. These complications have been discussed in several papers [O'Doherty and Anstey, 1971; Swan, 1991], and some of the major factors are (1) reflection coefficient, (2) the encasing sediments, (3) spherical spreading, (4) source and receiver array attenuation, (5) event tuning, (6) interface geometry (smooth versus complex boundary), (7) structure, (8) anisotropy, (9) noise, (10) residual normal moveout (NMO), and (11) processing. The reflection coefficient, or the relative change in reflection coefficient, is the factor we would like to observe. It is difficult to isolate and remove many of the different causes that affect the AVO response. The interactive AVO method does, however, allow us to identify the effects of some [Soroka and Reilly, 1992]. For example, low signal to noise ratio and interference effects caused by strong out-ofplane coherent noise or thin bed tuning can often be identified with the interactive AVO approach. Detailed examination of the common depthpoint (CDP) gathers will help to judge the quality and significance of AVO results.

We have restricted the AVO analysis to sections of the line where both the BSR and the seafloor reflector are relatively smooth and flat (Figure 2c), so that no dip correction was required. The prestack data were carefully examined, and only CDP gathers where the BSR is a single symmetric pulse at all offsets were selected for AVO analysis, in order to minimize interference effects with other reflections.
The section of line 769 shown in Figure 2a was reprocessed for the AVO study to preserve relative amplitudes, and the following processing sequence was applied: common midpoint (CMP) sorting, spiking deconvolution, spherical divergence amplitude correction, bandpass filtering, detailed velocity analysis, and normal moveout correction. Spiking deconvolution was applied to produce a zero-phase output and collapse the wavelet as much as possible. This affects the waveform, but after having analyzed several gathers before and after deconvolution, we conclude that the shape of the AVO curve is not significantly changed. Detailed velocity analyses were made for every $20 \mathrm{CDP}$ or about every $1 \mathrm{~km}$ along the line. We then used two independent methods of offset-dependent ampiitude balancing to correct the gathers for array attenuation, and each are explained below.

\section{Amplitude Balancing}

Successful evaluation of AVO results requires that true amplitude-versus-offset data are obtained. To this end we have corrected the peak values of the relative BSR amplitudes in two ways: (1) by a deterministic method that corrects for hydrophone directivity and (2) statistically, by using the seafloor reflection as a reference calibration event.

Method 1: Correcting for receiver array directivity. Of the major factors that affect reflection amplitude as a function of offset, the most important factor for this study is the receiver array attenuation, because the receiver is an extended array and not a point receiver. The source, however, can be treated as a single point source because the five-element source array was 

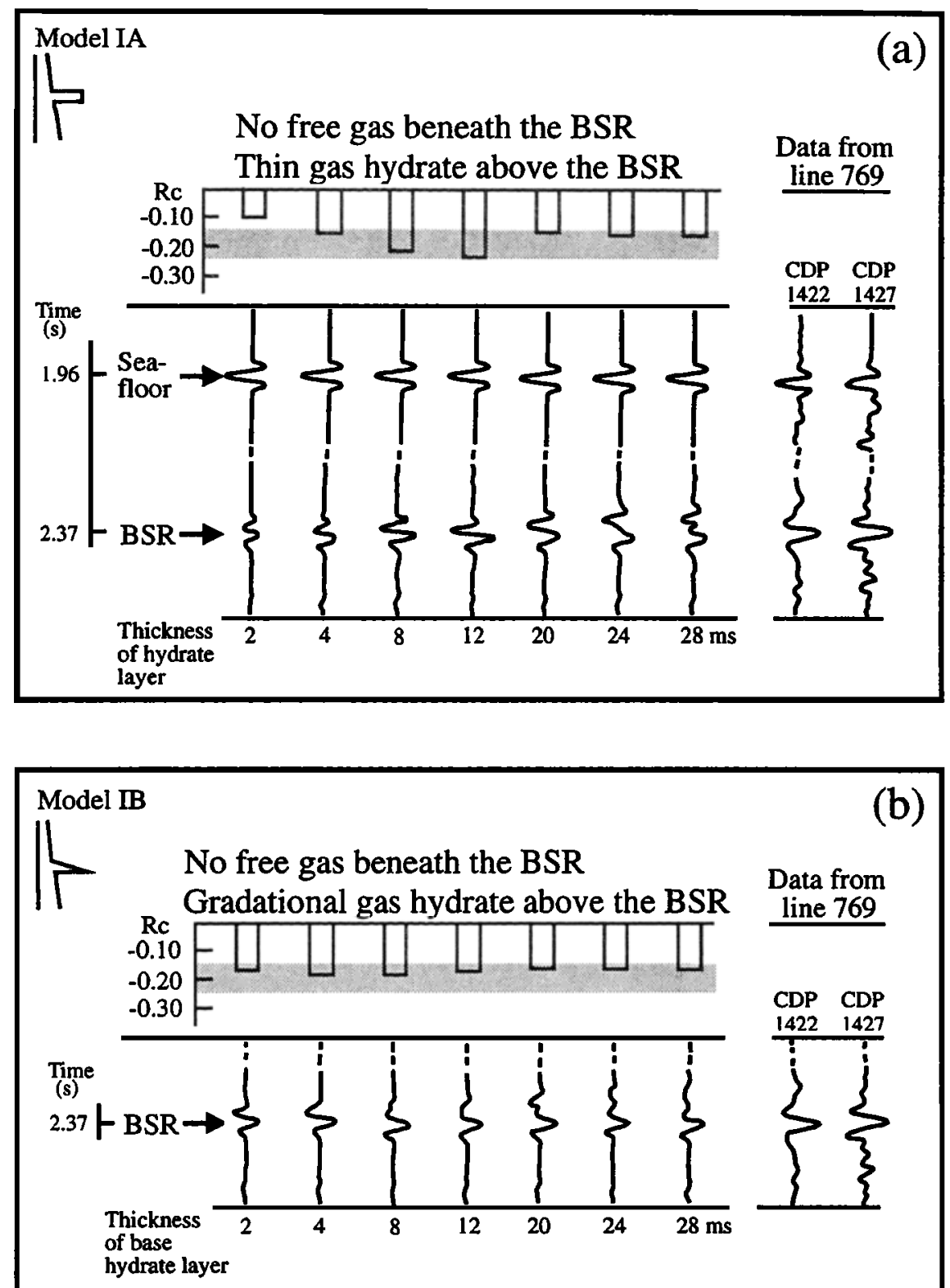

Figure 9. Near-vertical seismic traces produced from nodels with no free gas under the BSR and gas hydrate in the sediment over the BSR: (a) for models with a thin layer with uniform gas hydrate concentration; (b) for models with a thin layer of increasing concentration of gas hydrate with depth. The histograms above the traces indicate the calculated near-vertical reflection coefficient for each model, and the BSR reflection coefficients estimated from line 769 are indicated by the shaded band between -0.15 and -0.24 .

distributed cross-line, not inline, and thus, a source array correction is not needed. Hydrophone array attenuation is a function of incidence angle on the hydrophone array and was calculated using the function of Sheriff and Geldart [1982, p. 140].

Method 2: Trace normalization using the seafloor as a reference calibration event. The seafloor reflection in the study area is, in some places, a single, symmetrical zero-phase pulse, after the data have been deconvolved, which is characteristic of a reflection from a simple interface. The seafloor reflection from these areas is used as a reference event for offset-dependent balancing of the BSR amplitudes, as explained below.

Peak amplitudes of the seafloor reflection were measured interactively within CDP gathers from areas where this reflection is "good." A general AVO behavior of the seafloor reflection was estimated by smoothing the AVO response of these gathers.

The AVO response of the seafloor reflection was then modeled by using the following estimates of the elastic properties at the seafloor: (1) A small contrast in compressional velocity across this interface, from $1460 \mathrm{~m} / \mathrm{s}$ for the seawater to about $1500-1600 \mathrm{~m} / \mathrm{s}$ for the seafloor sediments (obtained from Hamilton [1978]); (2) density across this boundary is assumed to increase from approximately $1020 \mathrm{~kg} / \mathrm{m}^{3}$ in the water column to about $1600-1700 \mathrm{~kg} / \mathrm{m}^{3}$ for the shallowmost sediments (estimated from Hamilton [1978] and Hamilton and Bachman [1982]); (3) Poisson's ratio of $0.49-0.48$ is estimated for the 

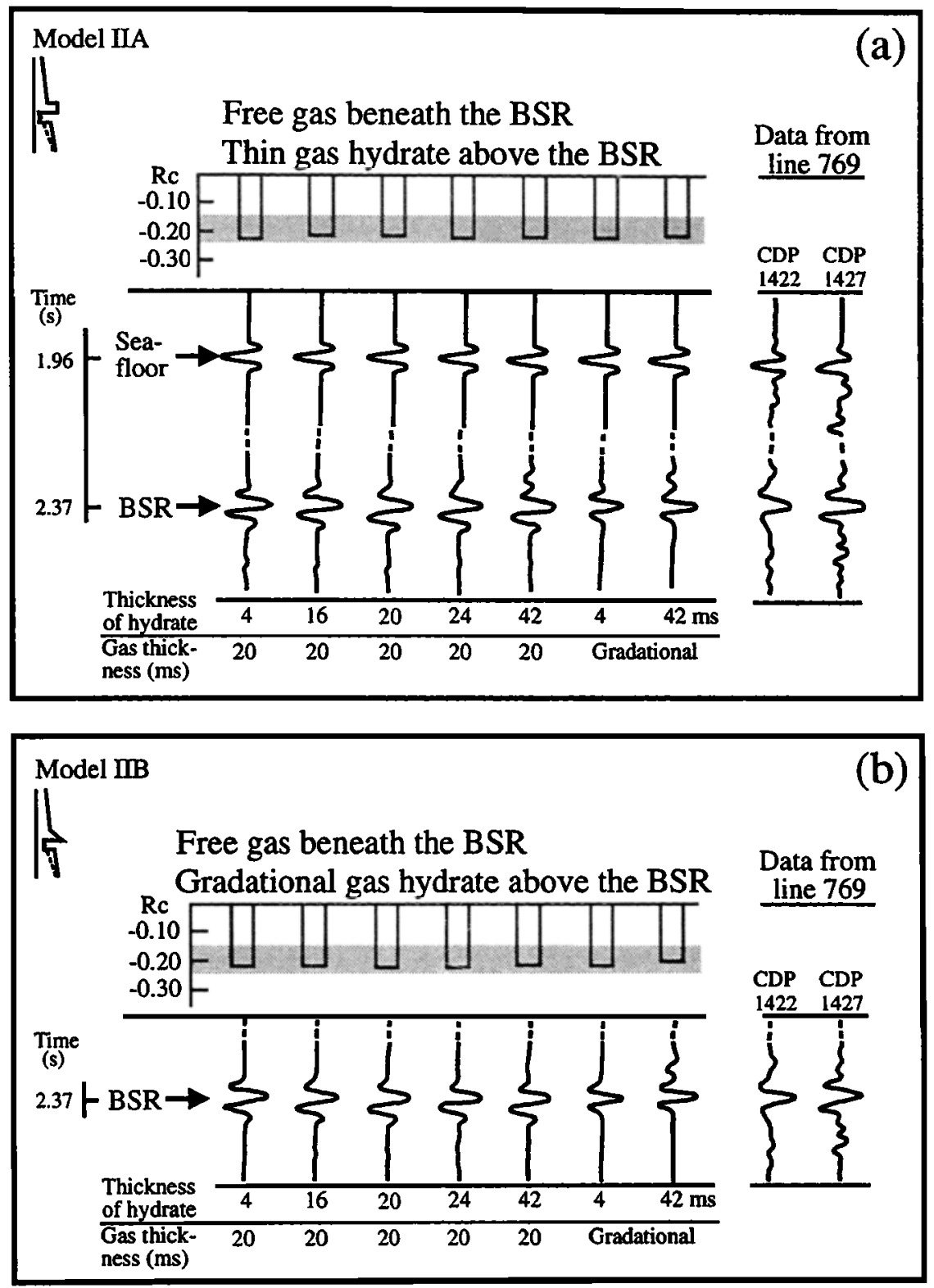

Figure 10. Near-vertical seismic traces produced from models with free gas under the BSR: (a) for models with a thin layer with uniform gas hydrate concentration in the sediments above the BSR; (b) for models with a thin layer with increasing concentration of gas hydrate with depth in the sediment above the BSR; (c) for models with no gas hydrate in the sediment above the BSR. The histograms above the traces indicate the calculated near-vertical reflection coefficient for each model, and the BSR reflection coefficients estimated from line 769 are indicated by the shaded band between -0.15 and -0.24 .

seafloor sediments [from Castagna et al., 1985; Hamilton, 1979].

A correction function, for offset-dependent balancing, was calculated from comparison of the observed, smoothed AVO response of the seafloor reflection and the theoretical AVO response. Ratios for the observed seafloor AVO response to the theoretical seafloor AVO response were calculated for each trace of the two CDP gathers and used as a correction function with incidence angle for balancing the BSR amplitudes. Using a reference event to restore the reflection amplitudes with offset is an alternative or a supplement to deterministic methods requiring complex or undeterminable correction schemes [Chiburis, 1992; Ross and Beale, 1994].

\section{Observed AVO for the BSR}

Examples of CDP gathers, corrected for receiver array directivity, using method 1 from above, are shown in Figure 11 and illustrate the amplitude-versus-offset behavior of the BSR. A slight increase in relative BSR amplitude with offset was observed in several areas along the line 769 , but the following AVO analysis was, as before mentioned, restricted to sections of the line where both the BSR and the seafloor reflection are relatively smooth and flat. The average AVO trend for $10 \mathrm{CDP}$ gathers is displayed in Figures 12 and 13, where the result of using correction method 1 above is displayed as a thick solid line, and the result of method 2 above is displayed as a thick 


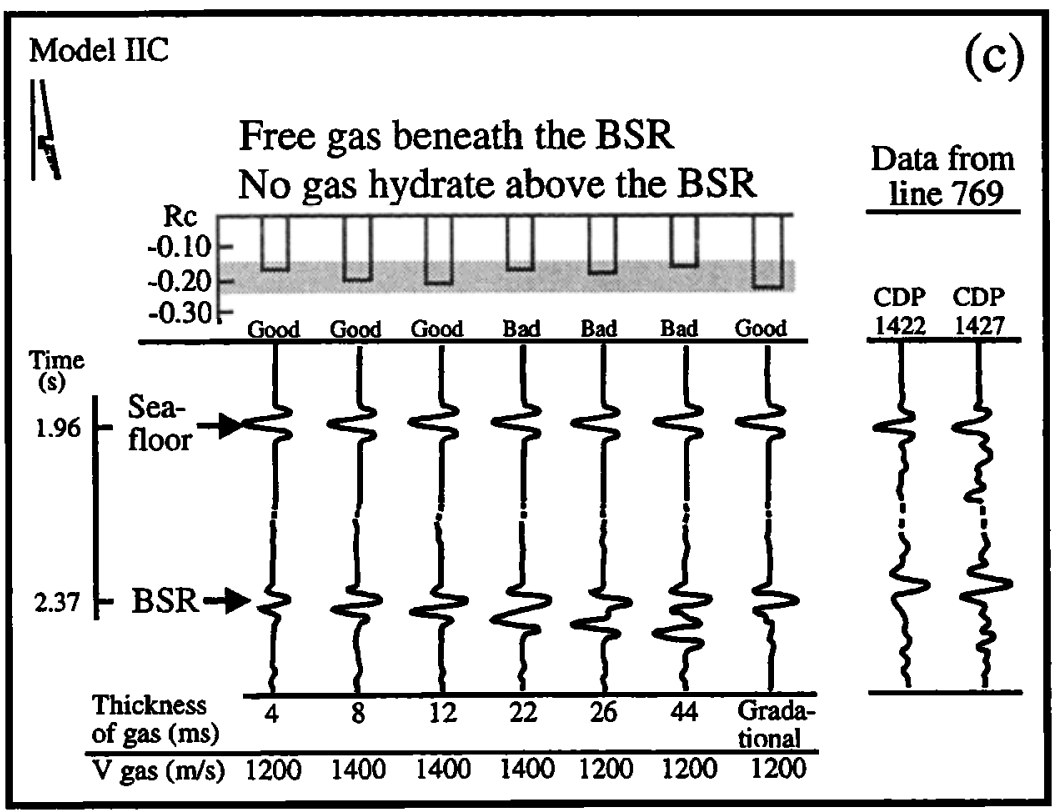

Figure 10. (continued)

dashed line. The general agreement of the two AVO averages, calculated by independent methods, provides assurance that our corrected data AVO trend for the BSR is valid. The corrected AVO averages exhibit a slight increase in relative amplitude to a factor of 1.8-1.9 at the far offset of $2300 \mathrm{~m}$, which corresponds to a BSR incidence angle of approximately 48 degrees.

\section{Modeling the BSR Amplitude With Offset}

The amplitude-versus-offset response was studied for the velocity models of Figure 8 using a PC AVO program from Hampson-Russell Software Services Ltd. Synthetic seismograms were generated by ray tracing and the Zoeppritz equations [Waters, 1987], accounting for mode conversion effects. Gradients of the model input parameters $V_{p}, \rho$ and $\sigma$ are approximated by thin homogenous layers, and interference effects are examined by varying the layer thicknesses from $2 \mathrm{~ms}$ to the wavelength of the seismic pulse used in the modeling, 44 ms.

Selection of appropriate Poisson's ratios is essential for realistic modeling of the AVO response. For water-saturated sediments at the depth of the BSR a Poisson's ratio of 0.47 is estimated from Figure 4 . For sediments partially saturated with free gas, minimum values of the Poisson's ratios are calculated from Figures 5,6 , and 7 , and since these are minimum estimates, slightly higher values are used in the modeling (Table 1). For models with no free gas beneath the BSR and a compressional wave velocity of $2600 \mathrm{~m} / \mathrm{s}$ for the hydratebearing sediments, a Poisson's ratio of 0.38 was used. We have for such models also examined the AVO effect when using a Poisson's ratio of $\mathbf{0 . 4 2}$, which was used by Hyndman and Spence [1992] and which we take as a reasonable upper limit for the Poisson's ratio of gas hydrate-bearing sediments with a $V_{p}$ of $2600 \mathrm{~m} / \mathrm{s}$.

The AVO response was studied for the five models illustrated in Figure 8. For each model a range of layer thicknesses, Poisson', ratios, and compressional wave velocities were used. The peak values of the modeled BSR amplitudes, digitized and normalized to the near trace amplitude peak, are displayed in Figures 12 and 13. The models with no free gas below the BSR exhibit an AVO trend that is very different from that observed in the data (Figures 12a and 12b). These models show a slight decrease in BSR amplitude for offsets up to $1300-1700 \mathrm{~m}$ and then an abrupt 3- to 4-fold amplitude increase. An exception was the model AVO curve in Figure 12a for a 20 -ms-thick gas hydrate layer (26 m of hydrate-bearing sediments with a velocity of $2600 \mathrm{~m} / \mathrm{s}$ ) and no free gas, which correlated well with the data for offsets up to $1800 \mathrm{~m}$ but which showed substantial deviation for larger offsets.

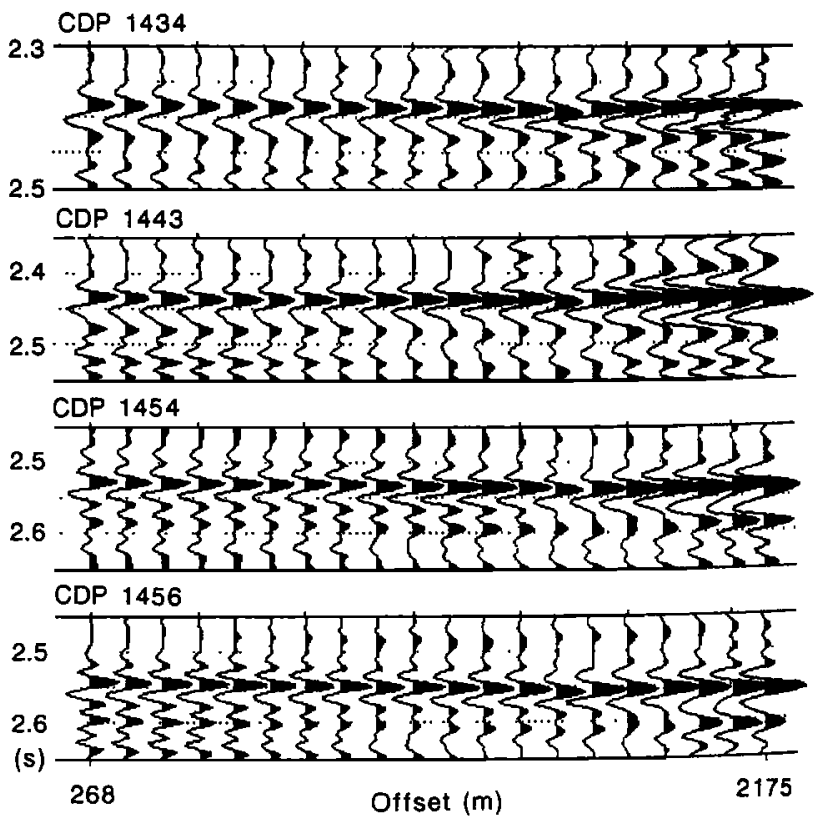

Figure 11. Common depthpoint (CDP) gathers with normal moveout from line 769 , illustrating amplitude-versus-offset (AVO) behavior of the BSR. The amplitudes have been corrected for receiver array directivity. 


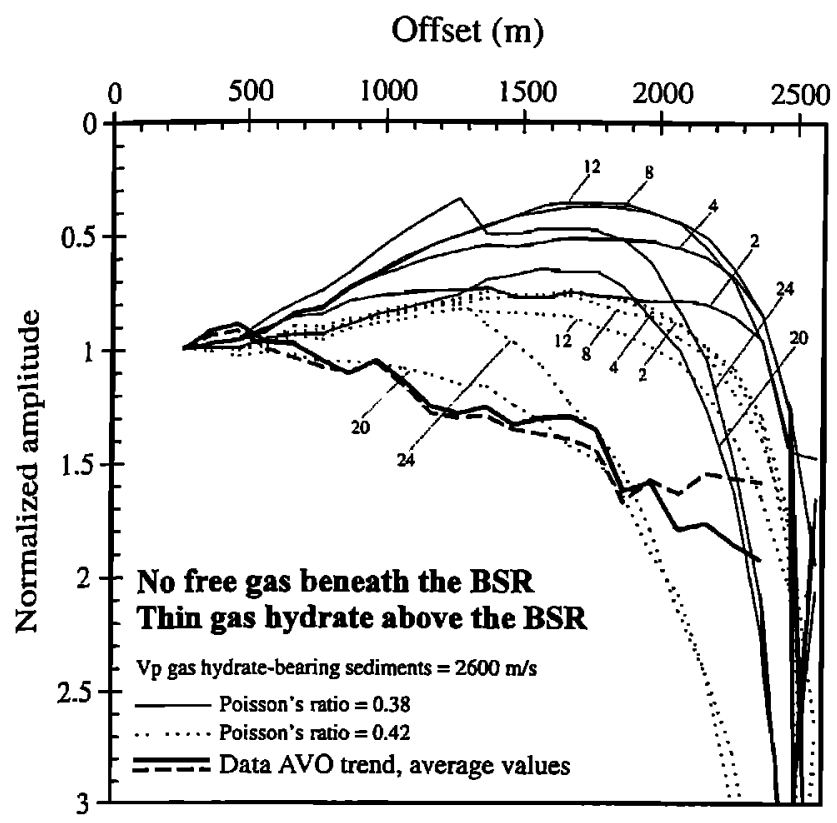

(a)

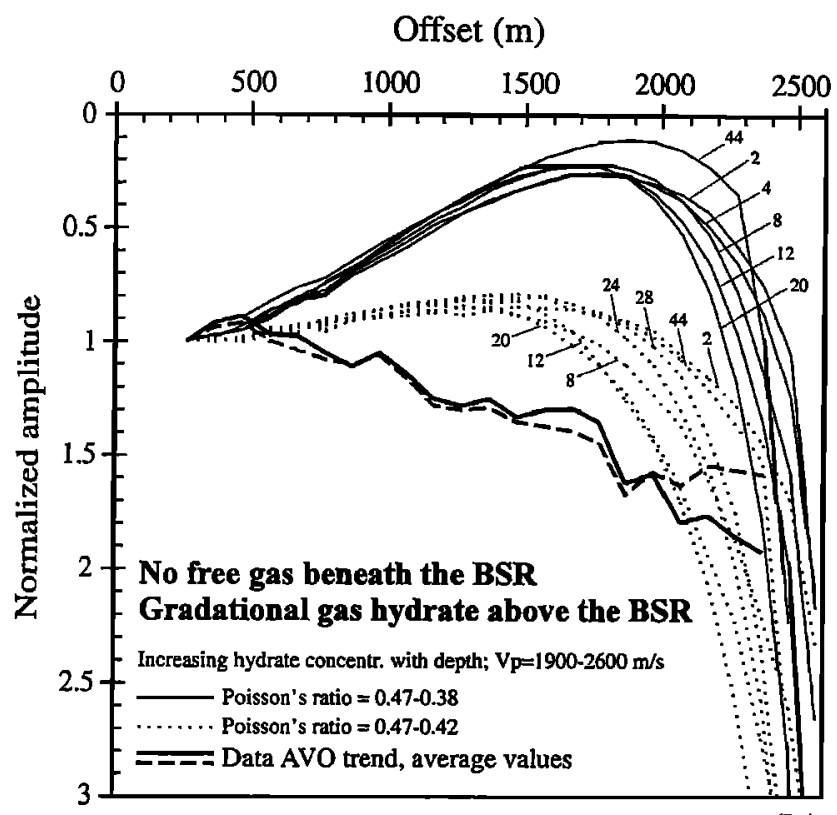

(b)

Figure 12. AVO trends for models with no free gas under the BSR and gas hydrate in the sediment over the BSR: (a) for models with a thin layer with uniform gas hydrate concentration; (b) for models with increasing concentration of gas hydrate with depth. The curves show peak values of the modeled BSR amplitudes that are normalized to the near-trace peak amplitude. Thickness of hydrate-bearing sediment is indicated by the numbers (in milliseconds) pointing to the lines. The average AVO trend for $10 \mathrm{CDP}$ gathers is calculated using two different methods for offset-dependent amplitude balancing, as explained in the text.

AVO curves for models with free gas in the sediment beneath the BSR show very good agreement with the AVO trend of the real data for both a thin layer of constant hydrate saturation (Figure 13a) and a thin layer with increasing hydrate concentration with depth (Figure 13b). Models with a thin layer of free gas in the sediments below the BSR and no hydrate above the BSR had a slightly higher rate of increase in the relative amplitude with offset (Figure 13c). A very good fit with the data was, however, also obtained for models with free gas and no overlying hydrate if the free gas concentration was decreasing with depth (Figure 13c, dashed line).

\section{Discussion}

The near-vertical incidence BSR response demonstrated a reasonable fit with the representative data traces for some of the models with no free gas beneath the BSR (Figure 9b) as well as for models with a free gas zone under the BSR (Figures 10a, $10 \mathrm{~b}$, and $10 \mathrm{c}$ ) and could not discriminate between models with and without free gas. The AVO method was more useful for this purpose. The BSR amplitude-versus-offset observed in the data could only be obtained for models with free gas in the sediments below the BSR, and such models gave, independently of the hydrate layer thickness, a good fit with the data (Figures 13a and 13b). Models with no free gas beneath the BSR did not correlate with the BSR amplitude-versus-offset data observations for any model thickness of the hydrate layer (Figures $12 \mathrm{a}$ and $12 \mathrm{~b}$ ). Changing the physical parameters, within reasonable limits, did not improve the correlation between the no-gas models and the data.

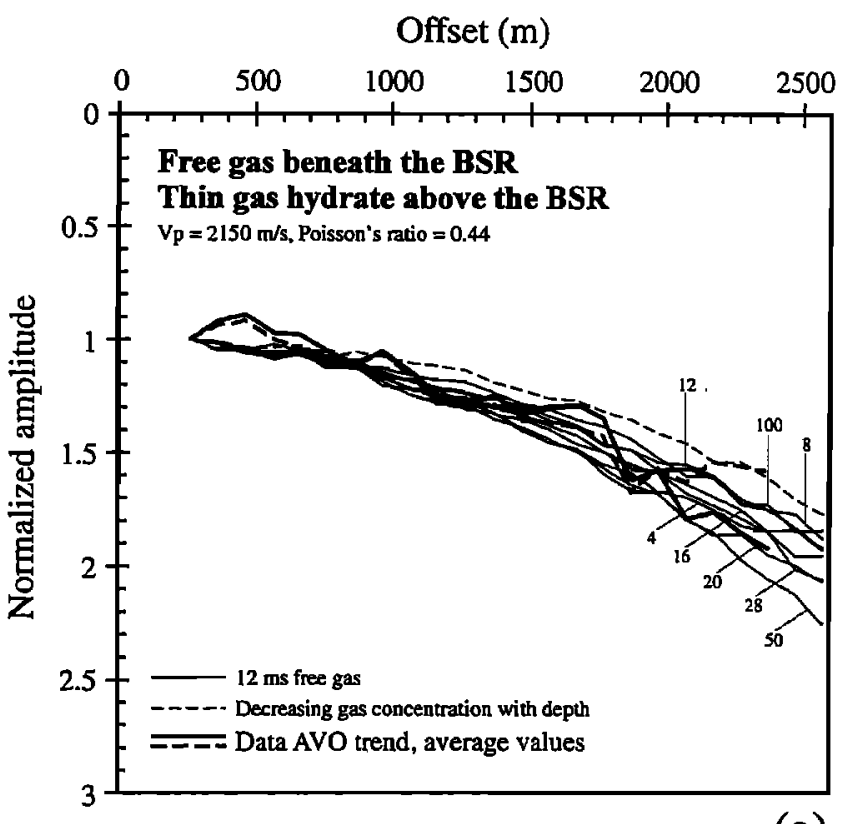

(a)

Figure 13. AVO trends for models with free gas in the sediments beneath the BSR: (a) for models witt a thin layer with uniform gas hydrate concentration in the sediment above the BSR; (b) for models with a layer with increasing concentration of gas hydrate with depth above the BSR; (c) for models with no gas hydrate in the sediment above the BSR. The curves show peak values of the modeled BSR amplitudes that are normalized to the near-trace peak amplitude. Thickness of hydrate-bearing sediment is indicated by the numbers (in milliseconds) pointing to the lines. The average AVO trend for $10 \mathrm{CDP}$ gathers is calculated using two different methods for offset-dependent amplitude balancing, as explained in the text. 


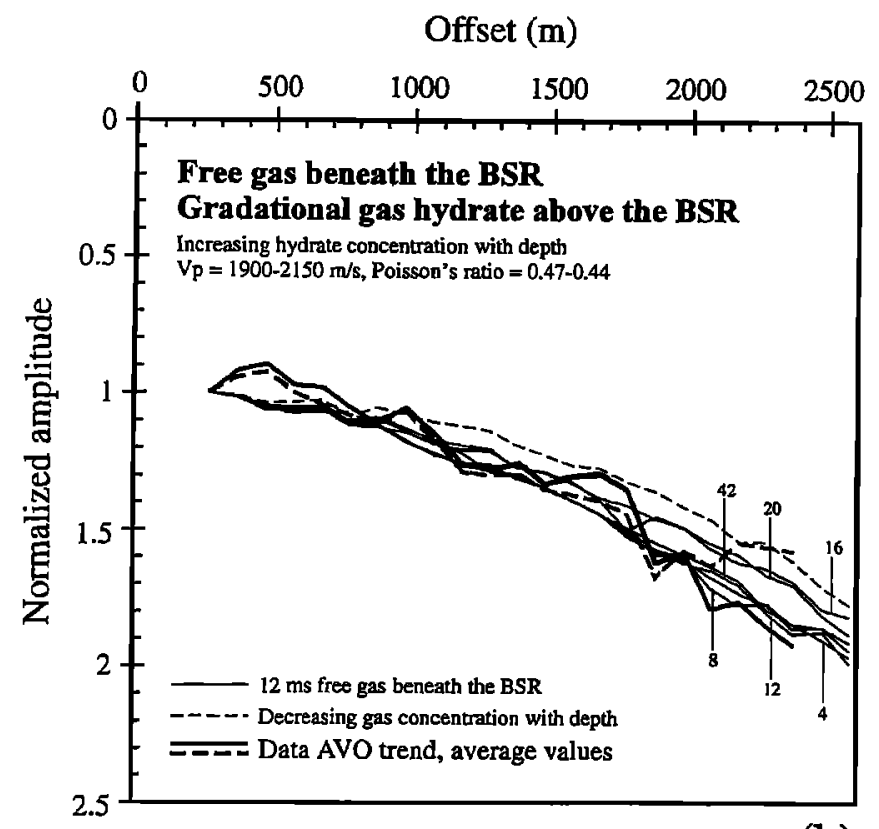

(b)

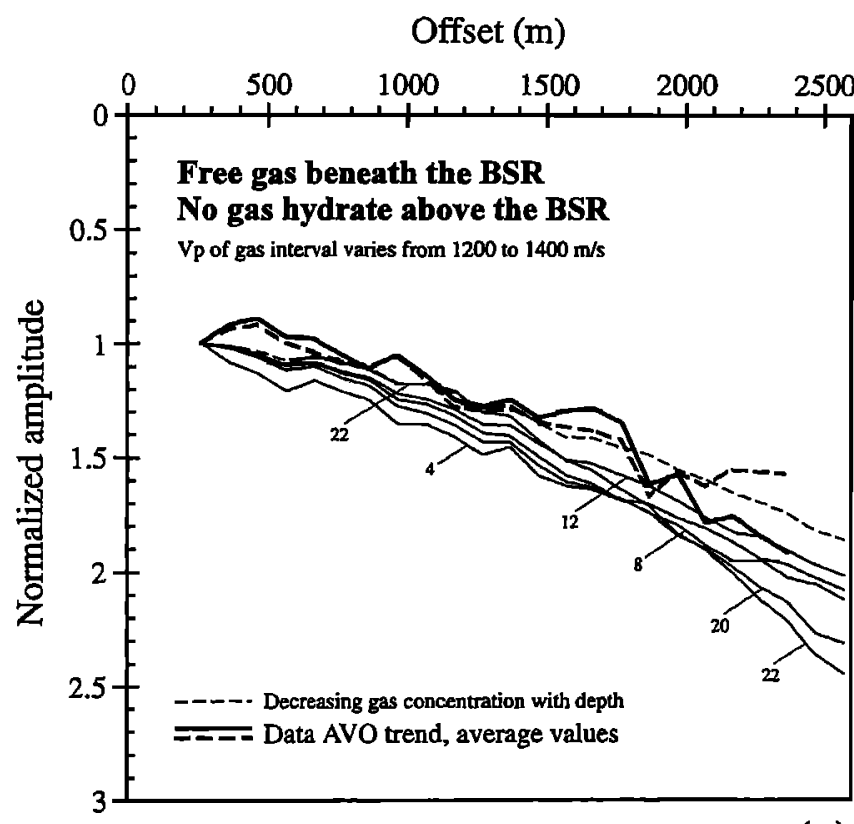

Figure 13. (continued)

(c)

\section{Free Gas Beneath the BSR}

For models with a free gas zone beneath the BSR, the high BSR reflection coefficient is primarily due to the extremely low compressional wave velocity for gas-bearing sediments. Even small amounts of free gas in the sediments cause a drastic reduction in the compressional velocity as well as in the Poisson's ratio, and the models with extremely low values of $V_{p}$ and $\sigma$ produce a distinctive trend of increasing amplitude with offset.

A good correlation with the Beaufort Sea field data was obtained when the thickness of free gas in the sediments beneath the BSR was thinner than 11-16 $\mathrm{m}$ or had a decreasing gas concentration with increasing depth. It is also possible that free gas beneath the BSR could be concentrated in several zones of varying gas concentration. Saturation levels of free gas in the sediments beneath the BSR cannot be inferred from the seismic data, because it is not possible to distinguish subtle differences in $V_{p}$ and $\sigma$ associated with gas concentrations above a few percent.

Increased amplitudes beneath the BSR of reflections that crosscut the BSR (Figure 2a) are commonly observed in the Beaufort Sea data and might also indicate the presence of free gas in the sediment layers beneath the BSR.

\section{Gas Hydrate Above the BSR}

Changes in elastic parameters for the zone above the BSR are small compared with the extreme changes of the underlying sediments partially saturated with free gas. This explains why changes in thickness or elastic moduli of the hydrate-bearing sediments did not substantially affect the modeled AVO behavior for free gas models and why good correlation with the data could be obtained for any hydrate thickness. Even models with no hydrate above the BSR showed an AVO trend very similar to that observed for the data, and a good fit was obtained for the no-hydrate model when the concentration of free gas was decreasing with increasing depth (Figure 13c, dashed line).

Hydrate saturation above the BSR can theoretically be estimated from compressional wave velocity, but this calculation cannot be used here since we do not know the concentration of free gas beneath the BSR. The AVO trend of the field data might, however, be used to tentatively estimate the hydrate saturation above the BSR. The AVO trend of the BSR is interpreted to result mainly from the $V_{p}$ and $\sigma$ contrasts across the BSR and is assumed not to be much affected by interference effects. We have in Figure 14 ignored interference effects from bedding planes close to the BSR and modeled the reflection coefficient versus offset for the single BSR interface, varying the concentrations of gas hydrate and free gas and using the curves of Figures 5 (Gassmann's equation), 6, and 7. The curves of Figure 14 are obtained from the Zoeppritz equation [Waters, 1987], and the reflection coefficient curve of the data (shaded band in Figure 14) is obtained from the estimated near-vertical reflection coefficients and from the average AVO trend of the data. It is demonstrated in Figures 14a and 14b that increasing saturation of gas hydrate above the BSR will change the AVO trend substantially, while increased saturation of free gas beneath the BSR will not affect the AVO curve significantly once the gas saturation is above approximately $1 \%$ (Figure 14c). The estimated AVO trend of the data (shaded band in Figures 14a and 14b) shows very good agreement with the modeled AVO curves for gas hydrate saturation between 0 and $10 \%$ (Figures 14a and 14b). For further increase in hydrate saturation, the modeled AVO curves show increased deviation from the AVO trend observed for the data.

Diminished reflection amplitude, or blanking, is commonly observed above the BSR along the Blake Ridge of the Atlantic continental margin of the United States [Dillon and Paull, 1983; Shipley et al., 1979; Lee et al., 1993], where it has been attributed to the presence of gas hydrate concentration in the order of 6-10\% of the total sediment volume [Lee et al., 1993], or $10-17 \%$ of the sediment pore volume. Blanking above the BSR is not commonly reported from other BSR locations. There might be indications in the Beaufort Sea data of a zone with diminished amplitude overlying the BSR, but it is difficult to decide if the lower amplitude above the BSR is an effect of increased amplitude of the reflections immediately beneath the BSR. 

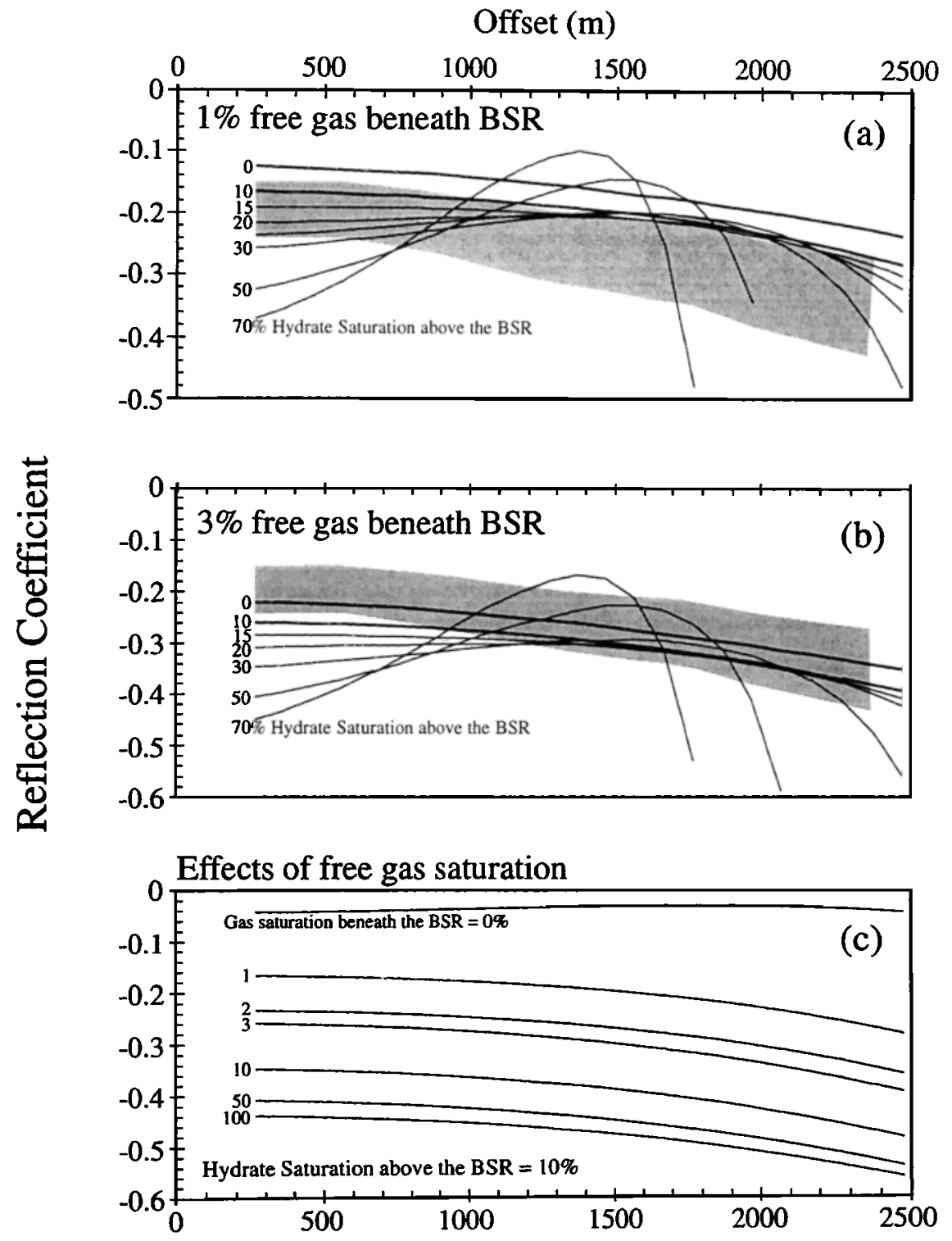

Figure 14. Calculated BSR reflection coefficients with offset, based on the velocity (Gassmann's [1951] equation) and density functions of Figures 5 and 7 and the Poisson's ratios of Figure 6: (a) for 1\% free gas beneath the BSR; (b) for $3 \%$ free gas beneath the BSR; (c) for $10 \%$ gas hydrate above the BSR. The small numbers next to the lines indicate in Figures $14 \mathrm{a}$ and $14 \mathrm{~b}$ saturation of gas hydrate above the BSR and in Figure $14 \mathrm{c}$ saturation of free gas beneath the BSR, in percent of the pore volume. Estimated reflection coefficients for the studied BSR of line 769 are indicated by the shaded band.

\section{Comparison With Results From Other Areas and Other Methods}

A low-velocity zone, inferring the presence of free gas beneath the BSR has also been observed in seismic data from offshore Peru [Miller et al., 1991], from the Blake Ridge area of the U.S. Atlantic margin [Lee et al., 1993] and from offshore Colombia [Minshull et al. , 1994]. Logging results from Ocean Drilling Program (ODP) sites suggest the presence of small amounts of free gas beneath the BSR, of the order of 1-5\% offshore Vancouver Island and offshore Oregon [MacKay et al., 1994] and approximately 1\% offshore Chile [Bangs et al., 1993]. Estimated thickness of the inferred free gas layer varies from $8 \mathrm{~m}$ offshore Chile to more than $50 \mathrm{~m}$ offshore Oregon. The presence of gas hydrate above the BSR, up to $10-20 \%$ of the pore space, has been suggested for these locations, but such concentrations of hydrate are too small to generate the large impedance contrasts required to match the observed BSR amplitudes. Instead, the low velocity caused by small concentrations of free gas beneath the BSR will explain the strong reflection associated with the base of the gas hydrate stability zone. The results from our study of the BSR beneath the Beaufort Sea are in accordance with such a BSR model.

Our study demonstrates that investigations of the BSR amplitude-versus-offset behavior can be a useful technique for detecting the presence of free gas in the sediment beneath the BSR but do not provide information about gas saturation levels. The AVO behavior of the BSR is quite sensitive to changes in saturation levels of gas hydrate in the sediment above the BSR and offers a first approach to estimating the amount of hydrate 
immediately above the BSR. A method based on the degree of amplitude blanking above the BSR, calibrated by interval velocity information, was recently proposed by Lee et al. [1993] to quantify gas hydrate concentrations in deep marine sediments. The AVO method does provide important complimentary $S$ wave information to information that can be obtained from velocity analysis or $P$ wave inversion, near-offset, or stacked data analyses.

Estimates of gas hydrate saturation can, however, without an appropriate physical property database or model for sediments partially saturated with gas hydrate, be nothing more than first tentative approaches. This emphasizes the need for research into how the physical properties of sediments are affected by the presence of gas hydrate.

\section{Conclusions}

We were able to discriminate between two competing models for the hydrate BSR by studying the amplitude and waveform at different source-receiver offsets for multichannel seismic data from a strong BSR segment beneath the Beaufort Sea margin north of Alaska. The two BSR models could not be distinguished by using only near-vertical seismic data.

The AVO trend of the models showing the best correlation with the field data was primarily a result of extremely low compressional wave velocity and Poisson's ratio of the sediments beneath the BSR, clearly indicating the existence of free gas. Near-vertical waveform and AVO modeling indicate that the free gas layer is either thinner than $11-16 \mathrm{~m}$ or has a gradational base with decreasing gas saturation with increasing depth. The AVO technique could not provide information about gas saturation levels.

Partial saturation of gas hydrate, up to approximately $10 \%$ of the sediment pore volume, provides a good explanation for the observed amplitude-versus-offset trend of the studied BSR. Thickness and detailed structure of the hydrate-bearing sediments could not be constrained.

Acknowledgments. We thank Eric Geist and Keith A. Kvenvolden for helpful comments on an earlier version of the manuscript and Deborah R. Hutchinson, Nathan L. Bangs, and John J. Miller for careful and constructive reviews. The first author benefited from a visit to U.S. Geological Survey, Menlo Park, Califomia, that was supported by a grant from the Norwegian Research Council for Science and Humanities (NFR). Jan P. Holm and Frøydis Strand made most of the drawings. We offer our sincere thanks.

\section{References}

Anstey, N.A., Seismic Interpretation: The Physical Aspects, 625 pp., International Human Resources Development Corporation, Boston, 1977.

Bangs, N.L.B., D.S. Sawyer, and X. Golovchenko, Free gas at the base of the gas hydrate zone in the vicinity of the Chile Triple Junction, Geology, 2I(10), 905-908, 1993.

Castagna, J.P., M.L. Batzle, and R.L. Eastwood, Relationship between compressional-wave and shear-wave velocities in clastic silicate rocks, Geophysics, 50, 571-581, 1985.

Chiburis, E.F., AVO applications in new exploration areas of Saudi Arabia, in How useful Is Amplitude-Versus-Offset (AVO) Analysis?, edited by J.H. Robinson, pp. 38-39, American Geophysical Union, Washington, 1992.

Curtis, W.R., Predicted geoacoustic properties of gas hydrate saturated marine sediments, Rep. 06192-A-31-100, 133 pp., Offshore Technol. Res. Cent., Texas A\&M Univ., College Station, 1992.

Dillon, W.P., and C.K. Paull, Marine gas hydrate, II, geophysical evidence, in Natural Gas Hydrates: Properties, Occurrence and
Recovery, edited by J.L. Cox, pp. 73-90, Butterworth-Heinemann, Stoneham, Mass., 1983.

Domenico, S.N., Effect of brine-gas mixture on velocity in an unconsolidated sand reservoir, Geophysics, 41, 882-894, 1976.

Domenico, S.N., Elastic properties of unconsolidated porous sand reservoirs, Geophysics, 42, 1339-1368, 1977.

Ecker, C., and D.E. Lumley, AVO analysis of methane hydrate seismic data, Eos Trans. AGU, 74(43), Fall Meet. Suppl., 370, 1993.

Gassmann, F., Uber die elastizitat poroser medien, Vierteljahrsschr. Naturforsch. Ges. Zuerich, 96, 1-13, 1951.

Grantz, A. G., and D.A. Dinter, Constraints of geological processes on western Beaufort Sea oil developments, Oil Gas J., 78, 18, 304 $319,1980$.

Grantz, A., D.M. Mann, and S.D. May, Tracklines of multichannel seismic-reflection data collected by the U.S. Geological Survey in the Beaufort and Chukchi Seas in 1977 for which profiles and stack tapes are available, U.S. Geol. Surv. Open File Rep. 82-735, 1 map sheet with text, 1982.

Grantz, A., S.D. May, and D.A. Dinter, Regional geology and petroleum potential of the United States Beaufort and northeasternmost Chukchi Seas, in Geology and Resource Potential of the Continental Margin of Western North America and Adjacent Ocean Basins -Beaufort Sea to Baja California, Earth Sci. Ser., vol. 6, edited by D.W. Scholl, A. Grantz, and J.G. Vedder, Pp. 17-35, Circum-pacific Council for Energy and Mineral Resources, Houston, Tex., 1987.

Grantz, A., S.D. May, and P.E. Hart, Geology of the Arctic continental margin of Alaska, in The Geology of North America, vol. L, The Arctic Ocean Region, edited by A. Grantz, L. Johnson, and J.F. Sweeney, pp. 257-288, Geological Society of America, Boulder, Colo., 1990.

Gregory, A.R., Aspects of rock physics from laboratory and log data that are important to interpretation, in Seismic Stratigraphy - Applications to Hydrocarbon Exploration, edited by C.E. Payton, AAPG Mem., 26, 15-46, 1977a.

Gregory, A.R., Fluid saturation effects on dynamic properties of sedimentary rocks, Geophysics, 41, 895-921, 1977b.

Hamilton, E.L., Sound velocity-density relations in sea-floor sediments and rocks, J. Acoust. Soc. Am., 63, 2, 366-377, 1978.

Hamilton, E.L., $V_{p} / V_{s}$ and Poisson's ratios in marine sediments and rocks, J. Acoust. Soc. Am., 66, 1093-1101, 1979.

Hamilton, E.L., and R.T. Bachman, Sound velocity and related properties of marine sediments, J. Acoust. Soc. Am., 72, 6, 18911904, 1982.

Hyndman, R.D., and G.D. Spence, A seismic study of methane hydrate marine bottom simulating reflectors, J. Geophys. Res., 97, 66836698, 1992.

Kayen, R.E., and H.J. Lee, Pleistocene slope instability of gas hydrateladen sediment on the Beaufort Sea margin, Mar. Geotechnol., 10, 125-141, 1991.

Kuster, G.T., and M.N. Toksöz, Velocity and attenuation of seismic waves in two-phase media, I, Theoretical formulations, Geophysics, 39, 587-606, 1974.

Kvenvolden, K.A., Methane hydrate - A major reservoir of carbon in the shallow geosphere?, Chem. Geol., 71, 41-51, 1988.

Kvenvolden, K.A., Gas hydrates - geological perspective and global change, Rev. Geophys., 31(2), 173-187, 1993.

Kvenvolden, K.A., and L.A. Barnard, Hydrates of natural gas in continental margins, in Studies of Continental Margin Geology, edited by J.S. Watkins and C.L. Drake, AAPG Mem., 34, 631-640, 1983.

Kvenvolden, K.A., and A. Grantz, Gas hydrates of the Arctic Ocean region, in The Geology of North America, vol. $L$, The Arctic Ocean Region, edited by A. Grantz, L. Johnson, and J.F. Sweeney, pp. 539-549, Geological Society of America, Boulder, Colo., 1990.

Kvenvolden. K.A., and T.J. McDonald, Gas hydrates of the Middle America Trench - Deep Sea Drilling Project Leg 84, Initial Rep. Deep Sea Drill. Proj., 84, 667-682, 1985.

Kvenvolden, K.A., G.D. Ginsburgh, and V.A. Soloviev, Worldwide distribution of subaquatic gas hydrates, Geo Mar. Lett., 13, 32-40, 1993.

Lee, M.W., D.R. Hutchinson, W.P. Dillon, J.J. Miller, W.F. Agena, and B.A. Swift, Method of estimating the amount of in situ gas 
hydrates in deep marine sediments, Mar. Pet. Geol., 10, 493-506, 1993.

MacKay, M.E., R.D. Jarrad, G.K. Westbrook, R.D. Hyndman, and the Shipboard Scientific Party of ODP Leg 146, Origin of bottom simulating reflectors: Geophysical evidence from the Cascadia accretionary prism, Geology, 22, 459-462, 1994.

MacLeod, M.K., Gas hydrates in ocean bottom sediments, AAPG Bull., 66, 2649-2662, 1982.

Magoon, L.B., and K.J. Bird, Evaluation of petroleum source rocks in the national Petroleum Reserve in Alaska, using organic-carbon content, hydrocarbon content, visual kerogen, and vitrinite reflectance, U.S. Geol. Surv. Prof. Pap. 1399, 381-450, 1988.

Mathews, M.A., and R. von Huene, Site 570 methane hydrate zone, Initial Rep. Deep Sea Drill. Proj., 84, 773-790, 1985.

McIver, R.D., Role of naturally occurring gas hydrates in sediment transport, AAPG Bull., 66, 789-792, 1982.

Miller, J.J., M.W. Lee, and R. von Huene, An analysis of a seismic reflection from the base of a gas hydrate zone, offshore Peru, AAPG Bull., 75, 910-924, 1991.

Minshull, T.A., S.C. Singh, and C.B. Westbrook, Seismic velocity structure at a gas hydrate reflector, offshore western Colombia, from full waveform inversion, J. Geophys. Res., 99, 4715-4734, 1994.

Murphy, W.F., Acoustic measures of partial gas saturation in tight sandstones, J. Geophys. Res., 89, 11,549-11,559, 1984.

O'Doherty, R.F., and N.A. Anstey, Reflections on amplitudes, Geophys. Prospetc., 19, 430-458, 1971.

Ostrander, W.J., Plane-wave reflection coefficients for gas sands at non normal angles of incidence, Geophysics, 49, 1637-1648, 1984.

Pandit, B.I., and M.S. King, A study of the effects of pore-water salinity on some physical properties of sedimentary rocks at permafrost temperatures, Can. J. Earth Sci., 16, 1566-1580, 1979.

Pearson, C., J. Murphy, and R. Hermes, Acoustic and resistivity measurements on rock samples containing textrahydrofuran hydrates: Laboratory analogues to natural gas hydrate deposits, $J$. Geophys. Res., 91, 132-138, 1986.

Ross, C.P., and P.L. Beale, Seismic offset balancing, Geophysics, 59 , 93-101, 1994.

Sheriff, R.E., and L.P. Geldart, Exploration Seismology, vol I, History,
Theory, Data Acquisition, Cambridge University Press, New York, 1982.

Shipley, T.H., M.H. Houston, R.T. Buffler, F.J. Shaub, K.J. McMillen, J.W. Ladd, and J.L. Worzel, Seismic evidence for widespread possible gas hydrate horizons on continental slopes and rises, AAPG Bull., 63, 2204-2213, 1979.

Singh, S.C., A.T. Minshull, and G.D. Spence, Velocity structure of a gas hydrate reflector, Science, 260, 204-207, 1993.

Sloan, D.E., Clathrate Hydrate of Natural Gases, Marcel Dekker," New York, 1990.

Soroka, W.L., and J.M. Reilly, Interactive AVO quality control: A quey element for successful AVO analysis, in How Useful Is Amplitude-Versus-Offset (AVO) Analysis?, edited by J.H. Robinson, pp. 237-245, American Geophysical Union, Washington, 1992.

Stoll, R.D., and G.M. Bryan, Physical properties of sediments containing gas hydrates, J. Geophys. Res., 84, 1629-1634, 1979.

Swan, H.W., Amplitude-versus-offset measurement errors in a finely layered medium, Geophysics, 56, 41-49, 1991.

Tissot, B.P., and D.H. Welte, Petroleum Formation and Occurrence, Springer-Verlag, New York, 1978.

Wamer, M., Absolute reflection coefficients from deep seismic reflections, Tectonophysics, 173, 15-23, 1990.

Waters, K.H., Reflection Seismology. A Tool for Energy Resource Exploration, 3rd ed., Wiley-Interscience, New York, 1987.

Whalley, E., Speed of longitudinal sound in clathrate hydrates, $J$. Geophys. Res., 85, 2539-2542, 1980.

Zimmerman, R.W., and M.S. King, The effect of the extent of freezing on seismic velocities in unconsolidated permafrost, Geophysics, 51, 1285-1290, 1986 .

K. Andreassen, Institute of Biology and Geology, University of Troms $\varnothing$, N-9037 Troms $\varnothing$, Norway. (e-mail: karina@ibg.vit.no).

P. E. Hart and A. Grant, U.S. Geological Survey, 345 Middlefield Road, Menlo Park, CA 94025. (e-mail: hart@octopus.wr.usgs.gov)

(Received October 25, 1994; revised March 13, 1995; accepted March 20, 1995.) 